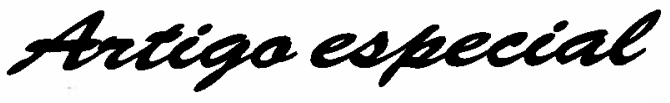

1. Introdução;

2. Definindo estratégias;

3. Racionalizar operações;

4. Compre o que quiser: o Banespa paga;

5. Os objetivos foram atingidos;

6. Saque especial: outro produto de sucesso;

7. Uma forma simples e descomplicada do uso do

marketing mix. Uma receita de sucesso.

\section{Marketing de serviços: estudo de um caso}

Henrique Pereira Gomes

Presidente da Financeira Banespa.

Diretor do Liceu de Artes e Ofícios de São Paulo.

\section{INTRODUÇÃO}

O mundo do marketing apresenta fatos bastante curiosos. Às vezes, uma grande idéia a respeito de criação, lançamento, ou mesmo adequação de um produto já existente no mercado, fruto de um longo e complicado trabalho de pesquisa, não encontra nenhuma ressonância junto ao público para o qual ele foi desenvolvido.

Cabe aí analisar mais detalhadamente todo o processo percorrido, a fim de serem detectadas as falhas, que podem ser: lançamento feito em época não propícia de mercado; falta de uma reestruturação interna para atender a demanda; inadequação do produto; inadequação dos pontos de venda para sua distribuição; trabalho falho de comunicação. E mais uma série de itens que só podem ser analisados se realmente tivermos em mãos um fato concreto.

Por outro lado, existem ocasiões em que uma idéia bastante simples, cujo produto final é tão óbvio que nos leva a questionar por que não fomos nós que a tivemos, acaba por se transformar em caso de sucesso mercadológico. Por que isso ocorre?

É esta a resposta que pretendemos dar neste artigo, contando minuciosamente a história de sucesso da Financeira do Banespa, que ao entender as necessidades de seu mercado acabou por lançar produtos extremamente simples, suprindo uma demanda emergente $e$ colocando sua financeira em quarto lugar no ranking das maiores financeiras do País. É importante ressaltar, também, que isto foi conseguido sem necessidade de aumentar recursos então disponíveis, inclusive de pessoal; ao contrário, houve redução de custos e racionalização das operações.

O lançamento de um produto, por mais simples e óbvio que possa parecer, mesmo tendo um espaço de mercado à disposição, certamente estará sujeito ao fracasso, se não forem observadas algumas regras básicas para sua sustentação. Dentre elas destacamos a própria estrutura interna da empresa e a utilização racional dos recursos disponíveis, a motivação de seus funcionários, a adequação do produto ao mercado e uma comunicação eficiente para o lançamento. Estes são alguns dos fatores que apresentamos neste artigo.

\section{DEFININDO ESTRATÉGIAS}

Logo ao assumir a administração do Banco do Estado de São Paulo (Banespa), uma das preocupações e metas da atual Diretoria relacionava-se com a financeira. Era preciso fazê-la crescer, torná-la condizente com o tamanho do banco, viabilizando a oferta de seus produtos.

Nessa época, março de 1983, o Banespa tomava nova postura, desenvolvendo agressivamente a alocação de recursos no mercado, a Poupança Especial Banespa. Havia toda uma administração voltada para colocação de seus papéis e aplicações, suas operações ativas, enfim, uma nova filosofia de conquista de mercado. No caso da financeira, precisava então haver uma adequação, estabelecer um equilíbrio entre a venda de letras de câmbio e $o$ volume de financiamento. É modelo clássico, no mercado, que empresas coligadas colaborem bastante na formação do lucro do banco-conglomerado e a regra é muito simples: a instituição conglomerada (banco, corretora, distribuidora, banco de investimento e desenvolvimento, financeira, seguradora,etc.), oferecendo permanentemente todos os produtos e serviços, mantém o cliente ativo; este que hoje demanda crédito, amanhã vai estar investindo, comprando letras de câmbio, CDBs, RDBs, fundos de investimento ou renda fixa, ações, aplicando em poupança ou outros produtos. E a nossa financeira era pequena, uma das últimas do ranking do mercado dos conglomerados, oferecendo muito pouco aos correntistas e ao mercado.

Como torná-la grande? O que fazer para mudar esta situação num mercado altamente 
competitivo com grandes financeiras já consolidadas e oferecendo os mesmos produtos?

Este era o nosso desafio.

Na verdade, nós já tínhamos uma receita-modelo. Estudos demonstravam que linhas de crédito dos vários produtos, abertas aos seus correntistas, com atendimento ágil, sem burocracias e dando suporte ao financiamento de bens e serviços, atingiriam diretamente os anseios de uma população, então reprimida entre uma inflação em crescimento vertiginoso e uma renda que comprometia o poder aquisitivo.

A receita, portanto, tínhamos, restava-nos a dúvida de como lançar este produto, como implantá-lo e formar a estrutura necessária para sua consecução, considerando ainda que contávamos com alguns problemas relacionados com fatores como:

- prioridade para o uso dos recursos de sistemas eletrônicos (havia produtos no conglomerado que preteriam nossos desejos, em face de sua maior urgência de implantação);

- a própria falta de definições mais precisas do produto;

- o fator tempo;

- o treinamento da equipe de produção nos pontos de vendas. (agências).

\section{Estas, "heroicamente"} comandadas pelos gerentes, recebiam um volume muito grande de informações, em forma de módulos de operações, instruções transitórias, circulares, resoluções. Lançar mais um seria rigorosamente desaconselhável, pois não teriam eles tempo disponivel de absorvê-lo para a prática da venda. A carga de instruções que os gerentes $e$ funcionários recebiam tinha que ser diminuída, sem prejuízo da informação. Além desse problema, levamos em consideração que todos nós, ao buscar um financiamento, dirigimo-nos imediatamente ao gerente e ele nem sempre pode deixar de lado as tarefas às quais está-se dedicando, para atender um assunto de rotina. Em muitas ocasiões, clientes são obrigados a esperar o gerente se liberar, pois só querem falar com ele, quer pela natureza de sua operação, quer porque acreditam que somente na gerência haverá solução para suas dúvidas. $O$ gerente tem como função principal administrar e gerir a agência, promovendo novos negócios e solucionando as exceções. Precisariamos; portanto, vender ao cliente sem passar pela Gerência.

\section{RACIONALIZAR AS OPERAÇÕES}

A primeira tarefa que teríamos pela frente seria buscar a fórmula de simplificar as operações. Fomos, então, ouvir diretamente nossos colegas nas agências, levantar todos os problemas do seu dia-a-dia. Isto foi para nós uma experiência fundamental, pois

vive o banco, que surgem os problemas e a atenção da administração à linha de frente é o caminho para a solução.

Pudemos observar que existiam vários formulários para contratos, um para cada tipo de operação de crédito, cerca de sete modelos diferentes e mais a ficha de comando contábil, além do cadastro do cliente. Partindo desses dados, solicitamos à $O \& M$ que desenvolvesse uma máscara que, ao ser preenchidà, contemplasse todas as exigências. Passou-se a um contrato unificado, atendendo a todos os tipos de operações de financiamento, de maneira bastante simplificada.

$O$ passo seguinte seria descomplicar a vida do cliente, já iniciado no processo da simplificação dos contratos, menos leituras e assinaturas. Muito mais que na questão de cálculo de taxas, bastante complicada para o cliente, $o$ problema estava na adequação das prestações à sua renda. Ele raciocinava mais ou menos assim: "Preciso de Cz\$50 mil e tenho disponibilidade de pagar $\mathrm{Cz} \$ 9$ $\mathrm{mil} / \mathrm{mês}$. Será que isto é possivel? "Cabia então ao gerente verificar se, com as taxas existentes, era viável essa operação. Informação que nem sempre tinha em mãos, obrigando-o. a fazer consultas, cálculos num trabalho que se acabava tornando bastante moroso, dificultando a vida para ambos os lados.

\section{Qual a saida para isso?}

A solução foi a mais simples possível: oferecer ao cliente uma linha de crédito como empréstimo pessoal, até um limite preestabelecido, de acordo com a legislação vigente, com opções de pagamento variando de acordo com o número de prestações e já definido o valor desejado. Tudo isso sem precisar ficar discutindo ou explicando taxas. A partir daí, o cliente faria seu próprio plano, de acordo com suas necessidades e disponibilidades do orçamento.

Durante todo o

desenvolvimento deste processo, foi-se estreitando cada vez mais o contato da financeira com a rede, o ponto de distribuição do produto. Era preciso inseri-la dentro dessa rede, motivar o nosso pessoal a vender. lsto se fez através de freqüentes reuniões que as Diretorias Operacionais mantinham com os Regionais e Gerentes. Vender a idéia da Carteira Financeira do Conglomerado Banespa aos nossos funcionários foi uma primeira fase de venda desse produto. Criou-se a mentalidade de conglomerado, conscientizando a todos de que estávamos trabalhando para uma única instituição, com uma só gestão e a carteira de operações de financeira era "banco pessoa física". Esta iniciativa mercadológica foi muito importante. Tínhamos naquele momento que sacudir o pessoal nas agências, fazer uma nova adequação, criar fatos novos, e motivar e gerar uma nova dinâmica no espírito de nossos funcionários.

Sem necessidade de aumentar pessoal e ainda obtendo redução significativa de custos, decorrente da racionalização das tarefas, estávamos nos antecipando, através da financeira, à filosofia do banco múltiplo que opera em todas as carteiras e segmentos do 


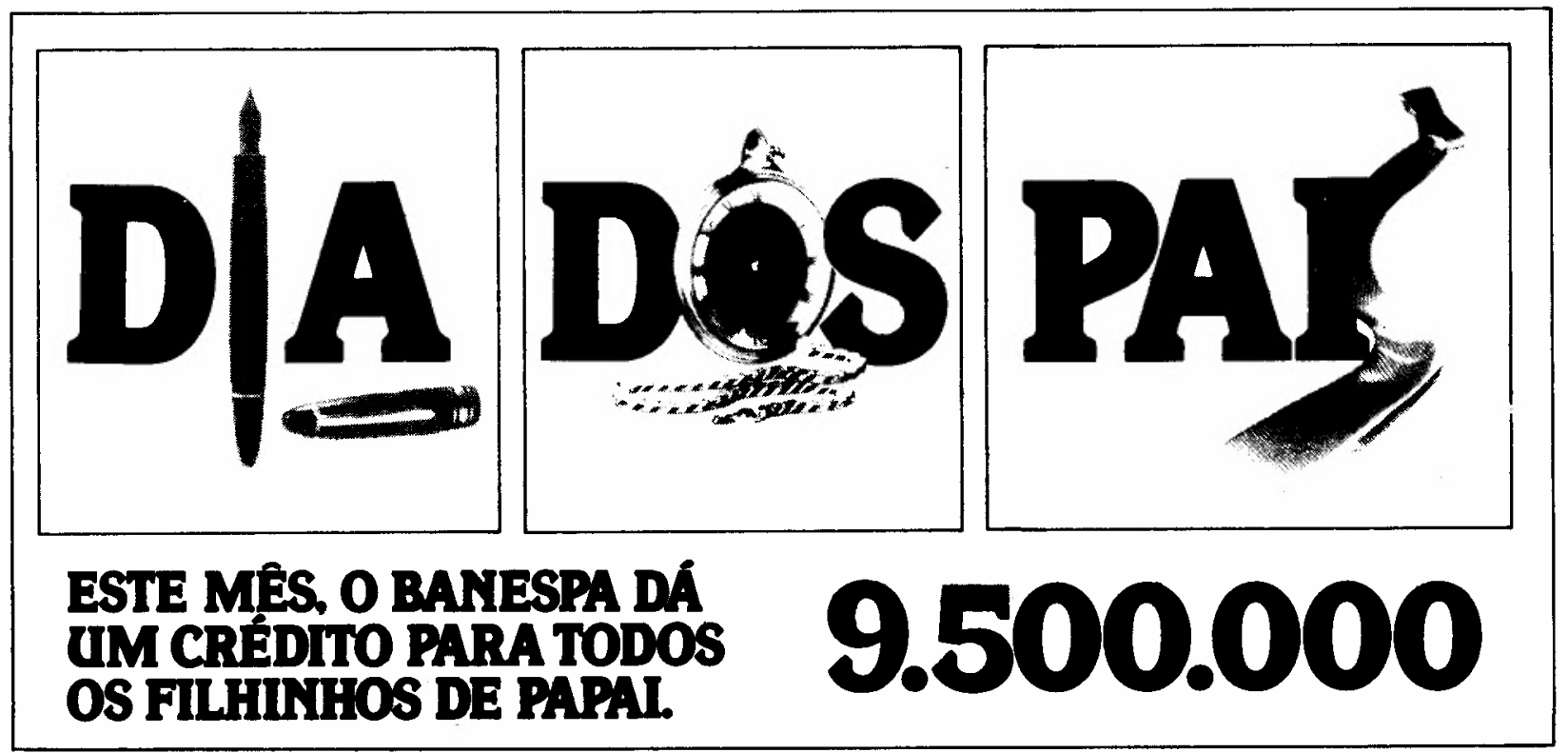

mercado financeiro. Restava, agora, lançar o produto, vendê-lo aos nossos clientes. Esta tarefa desenvolvemos com nossa agência de propaganda, SGB Publicidade e Promoções, responsável pelas campanhas promocionais de todos os produtos do conglomerado.

\section{COMPRE O QUE QUISER: $O$ BANESPA PAGA}

O nosso briefing era mais ou menos assim: temos um produto que vai ao encontro dos anseios de nosso público, ou seja, dinheiro. O nosso produto é igual ao que quase todas as financeiras que estão operando no mercado oferecem. Mas ao mesmo tempo ele é diferente, porque é simples, direto e descomplicado. Eram itens de destaque os seguintes:

- oferecer esse crédito diretamente aos nossos correntistas;

- dizer-lhes que não precisariam ficar perguntando como funcionava, eles mesmos iriam fazer os seus planos;

- dizer-lhes que o seu crédito já estava aberto, era só pegar o dinheiro;

- que encontrariam na agência todo um clima favorável para recepcioná-los, de forma tranqüila e descomplicada.

Essas informações tinham que ser passadas aos nossos clientes de uma forma que os estimulassem, sem constrangimento de solicitar o crédito. Quem vai buscar dinheiro num banco é porque realmente está precisando, porque está sem. Mas precisávamos transmitir isso a ele com uma mensagem do tipo: nosso negócio é financiar, se você quiser nosso financiamento, pode obtê-lo de forma simples.

Tínhamos de ser comunicativos. As taxas variavam mensalmente, de acordo com a ORTN e por isso nossas informações deveriam ser constantes.

Decidimos optar pelo sistema de mala direta, inserida junto com os extratos de conta corrente, que contemplava redução no custo de distribuição e postagem.

Iniciamos as reuniões de briefing. Formamos grupos com a participação das várias áreas da instituição (agência e administração); fomos muito felizes nos resultados e a agência criou peças promocionais que realmente atingiram os objetivos.

Desenvolvemos volantes coloridos com uma chamada na frente e mensagem no verso atrelada aos planos de pagamento. Os folhetos eram criados mensalmente e a agência começou a usar calendários promocionais. O primeiro deles referia-se ao Natal, férias,Carnaval, Dia das Mães, enfim, destacávamos as épocas mais propícias para a venda do crédito pessoal. Em agosto de 85 apresentamos o do Dia dos Pais, cuja chamada era assim: "Este mês, o Banespa dá um crédito para todos os filhinhos de papai: Cr\$9.500.000."

No verso a mensagem: "Agosto é o mês do Dia dos Pais.

Aproveite a oportunidade para fazer uma surpresa para seu pai dando um presente muito especial. A Financeira Banespa está oferecendo um empréstimo pessoal de até Cr $\$ 9.500 .000 .0$ pagamento pode ser feito em até 12 meses e você só começa a pagar a partir de setembro. E, para quem tem Cheque Especial Banespa, o crédito já está aberto e o depósito na sua conta é imediato.

A Financeira Banespa também tem outras linhas de financiamento, diferentes do crédito pessoal, e que podem ser pagas em até 24 meses. É para você comprar automóveis, vídeo-cassetes, motos, enfim, o que você quiser. Venha falar com a gente." Acima vinha um quadro com as opções de pagamento.

As mensagens foram-se sucedendo mês a mês, alusivas a 
Figura 2

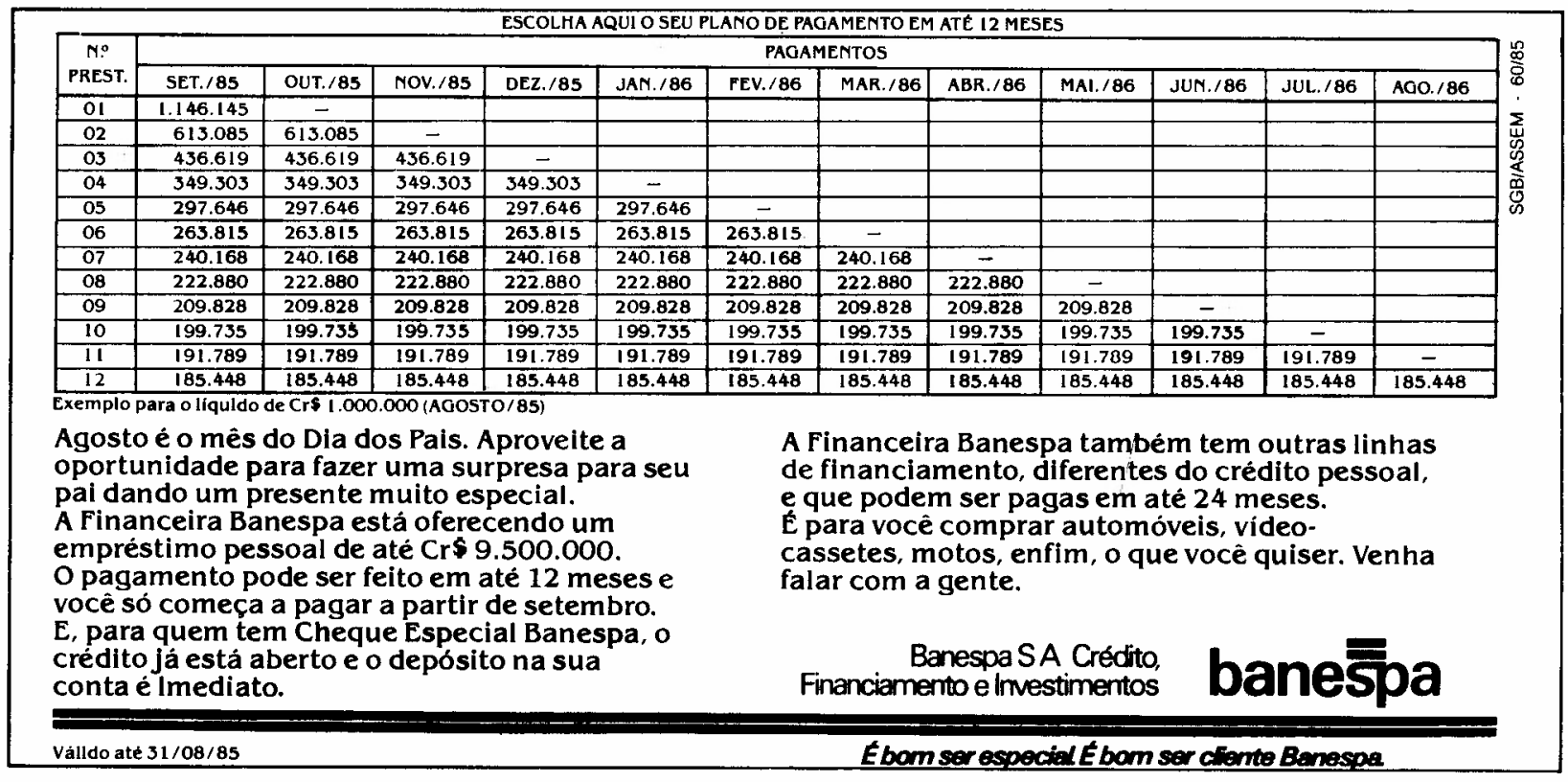

férias (figura 3), volta às aulas, dia dos namorados, e aproveitouse o volante para também divulgar outros produtos, como financiamento ae automóveis, construção e até seguros. Todos os motivos eram pesquisados para a circulação sistemática desses volantes, inclusive quadros, pinturas artísticas, feitos por funcionários do Banespa. Após a vigência do Plano Cruzado, eles continuaram circulando. Quando houve a limitação do prazo de financiamento para quatro meses, perdemos todo um lote de volantes que já estava impresso para 12. Mas este também foi um motivo para chamada de nossa mala direta. A SGB agiu rápido neste caso, e o volante reproduzia a manchete de um jornal que informava: "Crédito só em quatro meses." No rodapé inserimos nossa mensagem: "O prazo foi reduzido e o Banespa reduziu as taxas. Confira (Figura 5),"”

Os motivos para produção dos volantes iam-se renovando, como por exemplo o da série: "Não importa o seu tipo." Embaixo vinha uma seqüência de fotos, sendo um mês com rostos de pessoas com óculos dos mais variados tipos; em outros, homens com bigodes diferentes e assim sucessivamente. No rodapé a mensagem: " $\mathrm{C}$ Banespa tem todos os tipos de financiamento para você."

Para a impressão destes volantes o fator tempo sempre foi um obstáculo a ser vencido. Tínhamos que passar à agência até o dia 20 de cada mês os valores que seriam utilizados, para que a recepção ocorresse dentro do prazo correspondente. Eles eram enviados aos clientes do cheque especial e também espalhados pelas agências, para conhecimento dos outros correntistas. Além dos volantes, também foram criados posters para os pontos de venda.

Figura 3

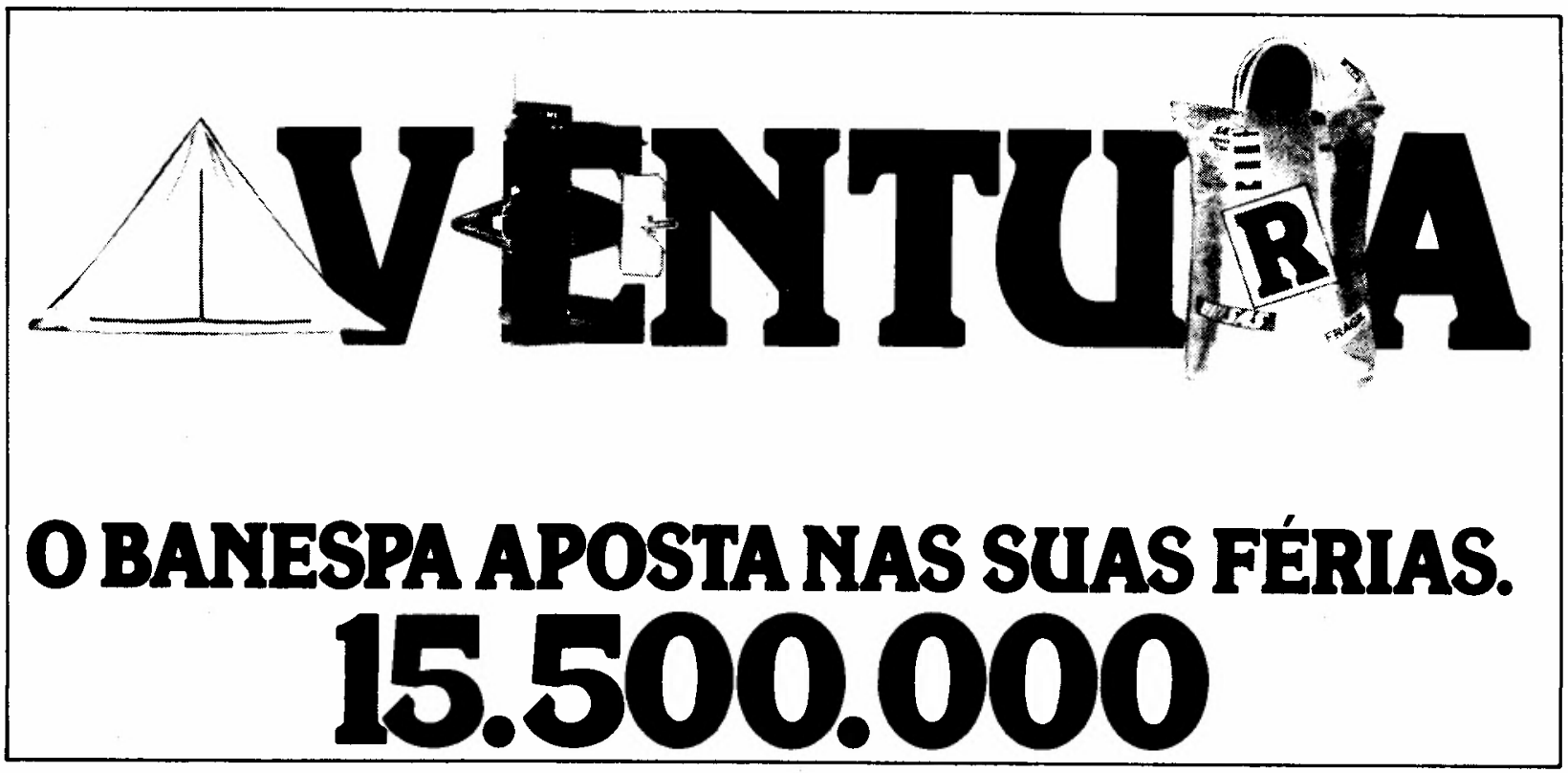




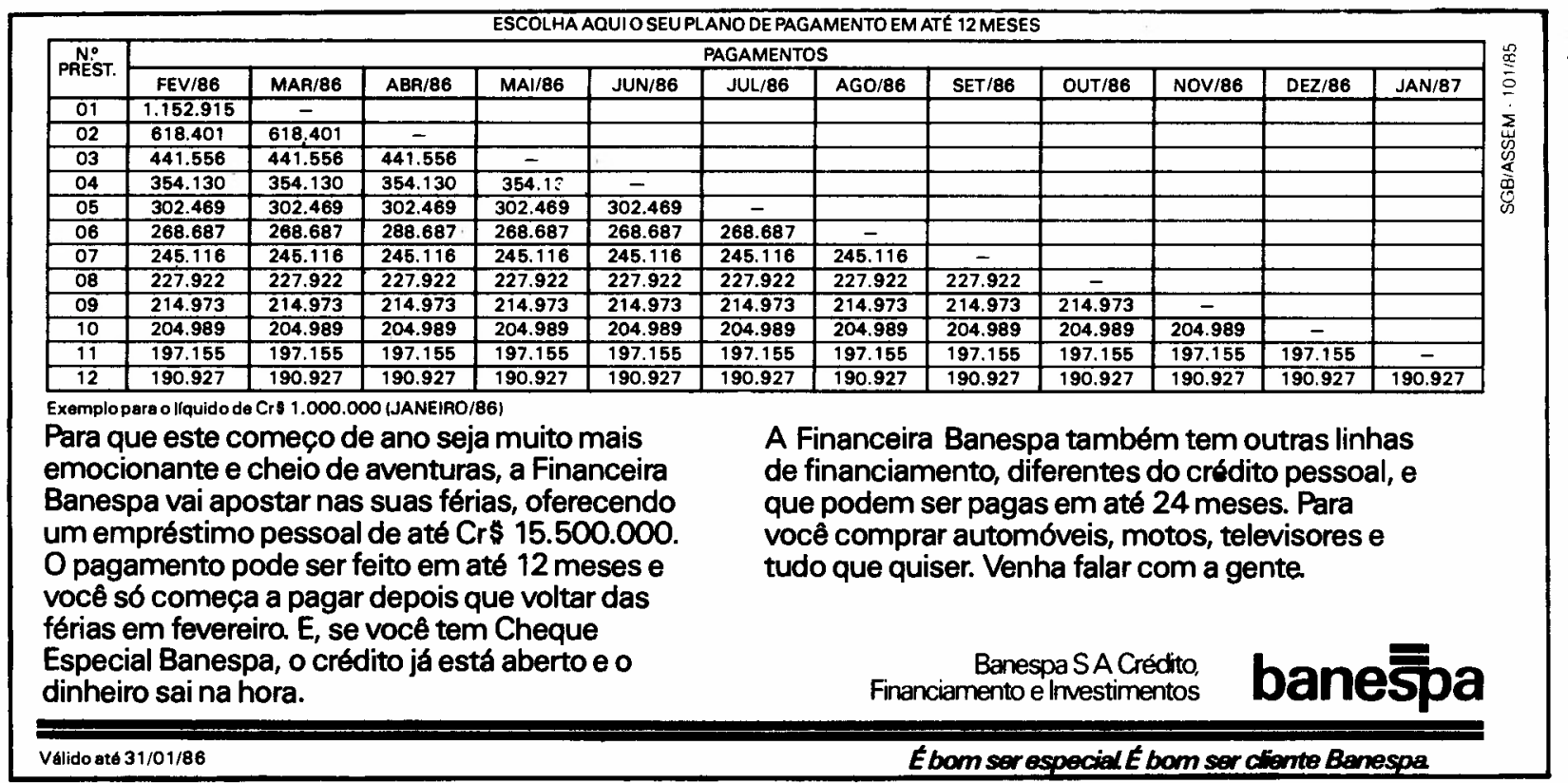

\section{OS OBJETIVOS FORAM ATINGIDOS}

Este empreendimento acabou-se transformando num grande sucesso. Conseguimos bater recorde de mercado e por dois anos consecutivos fomos considerados a "Financeira Número Um - Melhor Desempenho'.' Deve-se levar em conta que estávamos concorrendo com empresas de conglomerado que, atuando em todas as áreas, como leasing e seguros, tinham parte de sua produção operada pela financeira, além de situaremse em todo o País. Nós não tínhamos todos os produtos e nos restringimos, basicamente, ao estado de São Paulo.

Para se ter uma idéia do sucesso alcançado, em março de 1983, no ranking das 21 maiores financeiras do Pais, ocupávamos o 19. lugar.

Em março de 84 conseguimos o 13. lugar, março de 85 , o $11^{\circ}$, e março de 86 , o $5^{\circ}$. lugar, utilizando como critério de classificação o saldo das operações ativas, que reflete a evolução dos financiamentos. Para melhor análise deste item, o mesmo foi dividido em dois grupos: conglomerados e geral. Conglomerado inclui as financeiras que pertencem a bancos e Geral inclui também as financeiras independentes. Em maio de 86 , por exemplo, nossa posição era a seguinte:

Financiamentos (em $\mathrm{Cz} \$ \mathrm{mil})$

\begin{tabular}{ccc}
\hline Bancspa S.A. & Conglomerado & Geral \\
2.311 .750 & 41.440 .872 & 72.958 .341 \\
\hline
\end{tabular}

Em financiamentos, portanto, obtivemos $5,58 \%$ de participação no mercado, como conglomerado, e 3,17 como geral, ocupando em ambos os casos o quarto lugar.
Com relação à evolução dos títulos cambiais, dentro do mesmo raciocínio anterior e no mesmo mês, maio de 86 , era a seguinte a nossa posição:

Títulos cambiais

\begin{tabular}{ccc} 
Banespa S.A. & Conglomerado & Geral \\
1.168 .229 & 29.686 .004 & 39.408 .742 \\
\hline
\end{tabular}

Neste item detínhamos 3,94\% da participação do mercado dos conglomerados e 2,92 do geral, onde ocupamos a sexta colocação.

De março de 83 a abril de 86 , no ranking das 20 maiores financeiras do País, a nossa foi a que mais cresceu, em termos de participação real no mercado: $131,57 \%$. A tabela 1 ilustra as informações prestadas.

Até o surgimento do Plano Cruzado, o mercado apresentava taxas em elevações permanentes, variando conforme as ORTNs. $O$ Banespa foi e continua a ser a financeira que fornece as menore: taxas. Assim, cada vez que emitíamos um volante (este era válido por um mês), arriscávamos em relação à taxa. Era praticamente um prognóstico futuro, pois tínhamos que fornecer os valores para a agência de publicidade confeccionar os volantes. Mas qualquer que fosse o resultado, não recuávamos em nossa posição e mantínhamos nossa taxa, pois acreditávamos que era obrigação da financeira atender a demanda, o que ratificava e redimensionava a credibilidade do produto e da instituição. O que deixávamos de ganhar era o preço que tínhamos que pagar pela conquista e manutenção da imagem no mercado. 
Tabela 1

Evolução da participação real (base: março 1983) em $\mathrm{Cz} \$$ mil

\begin{tabular}{|c|c|c|c|c|c|c|}
\hline Empresa & Mar.83 & Mar.84 & Mar.85 & Mar.86 & Abr. 86 & $\begin{array}{c}\text { Abr.86/ } \\
\operatorname{mar} .83 \\
(\%)\end{array}$ \\
\hline Banespa & 26.568 & 31.707 & 41.602 & 50.279 & 61.523 & 131,57 \\
\hline Satira & 34.173 & 33.346 & 32.615 & 46.412 & 53.485 & 56,51 \\
\hline Unibanco & 50.705 & 63.229 & 66.523 & 81.887 & 71.755 & 41,51 \\
\hline Sinal & 26.588 & 35.669 & 53.199 & 34.475 & 33.850 & 27,31 \\
\hline 1:ininvest & 27.676 & 18.111 & 22.341 & 29.528 & 33.132 & 19,71 \\
\hline Real & 68.422 & 71.681 & 81.396 & 63.616 & 81.094 & 18,52 \\
\hline Bradesco & 210.032 & 195.867 & 218.060 & 207.796 & 238.249 & 13,43 \\
\hline Iiord & 51.726 & 49.631 & 65.632 & 40.647 & 40.818 & $-21,09$ \\
\hline liilasa & 83.946 & 45.279 & 58.931 & 43.663 & 49.592 & $-40,92$ \\
\hline ltaú & 204.926 & 193.471 & 160.875 & 85.158 & 113.872 & $-44,43$ \\
\hline Volks & 39.328 & 23.333 & 25.811 & 19.523 & 21.082 & $-46,39$ \\
\hline Batmerindus & 81.524 & 66.889 & 60.655 & 41.985 & 42.487 & $-47,88$ \\
\hline$G M$ & 83.824 & 65.897 & 60.032 & 43.495 & 43.399 & $-48,23$ \\
\hline Noroeste & 30.355 & 22.139 & 22.142 & 12.024 & 15.519 & $-48,87$ \\
\hline Mappin & 34.881 & 18.134 & 15.144 & 17.894 & 17.802 & $-48,96$ \\
\hline Lojicred & 19.143 & 9.897 & 6.935 & 8.891 & 9.091 & $-52,51$ \\
\hline Crefisul & 47.633 & 55.611 & 39.389 & 20.768 & 22.185 & $-53,42$ \\
\hline Ecunônico & 34.996 & 37.429 & 53.114 & 18.764 & 14.545 & $-58,44$ \\
\hline Credircal & 20.814 & 18.569 & 12.453 & 7.029 & 7.029 & $-66,23$ \\
\hline P. Açúcar & 34.905 & 12.716 & 6.477 & 10.075 & 10.075 & $-71,14$ \\
\hline
\end{tabular}

demanda deste mercado, através de uma linha de crédito emergencial para cobertura de saques, dirigidos exclusivamente a pessoas jurídicas. Com o saque, essas empresás têm agora crédito à disposição para utilização quando necessário. $O$ pagamento dos juros é feito somente sobre o valor e o periodo em que for utilizado. Funciona como qualquer cheque especial, só que com uma cobertura bem maior, que varia conforme o cadastro e $o$ saldo médio do cliente - fica a critério do gerente este limite.

A comunicação deste produto aos clientes foi feita por uma campanha publicitária criada pela $\mathrm{SGB}$, que incluiu dois filmes de um minuto, com quatro versões de 30 segundos, anúncios impressos, spots de rádio, broadsides e outras peças promocionais.
Hoje, podemos afirmar que o crescimento da nossa financeira deve-se exclusivamente à conquista de mercado. Obtivemos sucesso reduzindo custos e sem precisar aumentar pessoal. Conseguimos criar uma nova dinâmica que se traduziu em maior motivação dentro das agências, tendo a diretoria da financeira passado a trabalhar coordenada à diretoria do banco.

A contribuição no resultado da holding do banco passoc: a ser significativa, era um dos objetivos. A evolução foi crescente, como mostra o quadro seguinte, no qual evidenciamos que os números referentes ao primeiro semestre de 1986 foram fortemente impregnados e impactados com a reestruturação do sistema bancário, decorrente do Plano Cruzado, pelo que deverá ser considerado com reservas na série histórica apresentada.

\section{SAQUE ESPECIAL: OUTRO PRODUTO DE SUCESSO}

Este produto nasceu em decorrência da experiência da atuação da financeira. Além do mercado tradicional de pessoa física que estávamos atingindo,

\begin{tabular}{|c|c|c|c|}
\hline \multicolumn{4}{|c|}{$\begin{array}{c}\text { Quadro 1 } \\
\text { Participação da financeira no resultado do banco }\end{array}$} \\
\hline Período & Banco $^{\prime}$ & Financeira $^{2}$ & $\begin{array}{c}\text { Participação } \\
(\%)\end{array}$ \\
\hline $\begin{array}{l}1983 \\
1.0 \text { semestre } \\
2.0 \text { semestre }\end{array}$ & $\begin{array}{l}12.682 \\
26.985\end{array}$ & $\begin{array}{r}139 \\
1.262\end{array}$ & $\begin{array}{l}1,1 \\
4,7\end{array}$ \\
\hline $\begin{array}{l}1984 \\
1.0^{\circ} \text { semestre } \\
2.0 \text { semestre }\end{array}$ & $\begin{array}{l}53.490 \\
98.104\end{array}$ & $\begin{array}{r}5.683 \\
15.212\end{array}$ & $\begin{array}{l}10,6 \\
15,5\end{array}$ \\
\hline $\begin{array}{l}1985 \\
1.0 \text { semestre } \\
2.0 \text { semestre }\end{array}$ & $\begin{array}{l}234.816 \\
750.960\end{array}$ & $\begin{array}{r}46.801 \\
170.509\end{array}$ & $\begin{array}{l}19,9 \\
22,7\end{array}$ \\
\hline $\begin{array}{l}1986 \\
1 .^{\circ} \text { semestre }\end{array}$ & 154.667 & 107.346 & 69,4 \\
\hline
\end{tabular}

descobrimos que uma parcela dele era formada por "pessoas físicas proprietárias" de médias e pequenas empresas, que se utilizavam dessa linha de crédito pessoal para suas atividades empresariais. Essa operação era inadequada, porque não podia ser contabilizada pelo tomador.

Mas, em face de sua simplicidade operacional, era por eles preferida, o que nos fez questionar: por que não abrir uma linha de crédito para as mini, pequenas e médias empresas?

O Saque Especial, como foi batizado, surgiu para atender a
Os filmes exploram situações nas quais pequenos empresários são surpreendidos por acidentes involuntários que os acabam deixando sem fundo de caixa para continuarem tocando seus negócios. Esta, então, é a hora de procurar o Banespa. Estas cenas são enfocadas por um ângulo cômico em todos os filmes. Assim, encontra-se o dono de um armarinho entrando no banco, vestido apenas com um barril, depois de ter sido obrigado a saldar dívidas inadiáveis em sua loja. Ou um japonês, dono de uma pequena rotisserie, que entra 


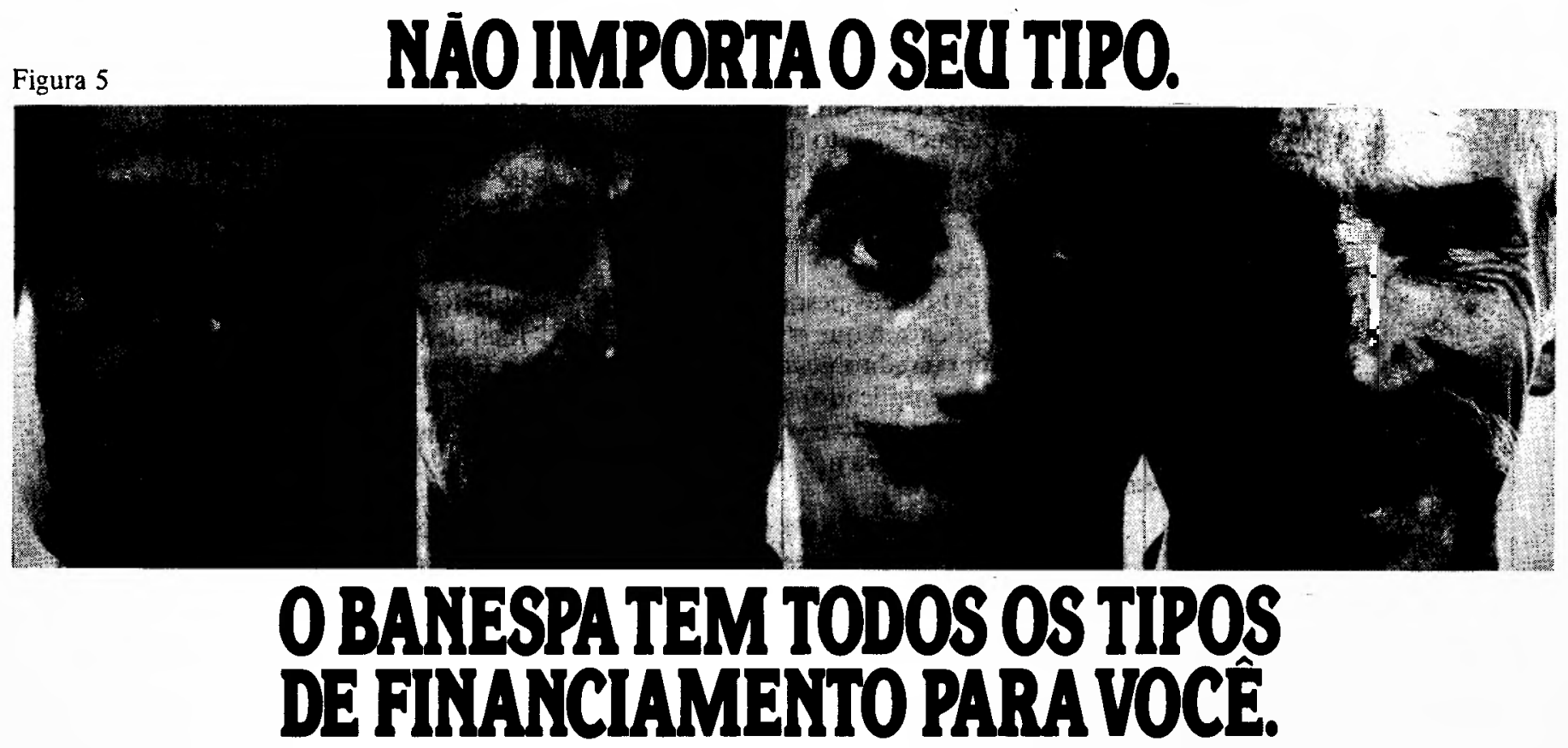

na agência com o rosto todo preto, espalhando fuligem pela mesa do gerente, em conseqüência da explosão de um de seus fornos. Ou ainda um pequeno industrial que tem atrás de si alguns operários fazendo gestos de apertar parafusos, alusão ao filme Tempos Modernos, de Charles Chaplin. Todos esses personagens acabam sempre se encontrando na agência, quando um sai, outro está entrando, e sempre fala, em tom irônico e olhando para a câmara: "Ele ainda não sacou, mas vai sacar."

Quando o produto tem atrás de si uma comunicação eficiente, ele praticamente passa a caminhar sozinho. No Saque Especial, a SGB, mais uma vez, foi muito feliz na criação da campanha. $O$ sucesso hoje é tanto do produto como de sua comunicação. A frase "ele ainda não sacou, mas vai sacar" caiu na boca do povo e é usada sob as mais diferentes formas. Até mesmo os chargistas dos grandes jornais já a usaram para tratar com humor os grandes temas nacionais.

A comunicação deste produto foi trabalhada em todos os seus detalhes. Para a confecção das capas dos talões de cheques, foi realizada uma pesquisa

fotográfica que retrata o início e o desenvolvimento da indústria e do comércio de São Paulo, a partir de
1900. Antes mesmo de estarem prontos, enviamos uma comunicação aos nơssos clientes, pessoas jurídicas, através de um envelope que mostrava como eles seriam. No verso do envelope colocamos a seguinte mensagem: "Prezado cliente, o Banespa coloca em suas mãos um produto inédito: o Saque Especial

Banespa. Trata-se de um cheque especial para empresas, criado para of erecer um crédito fácil que você usa quando precisar e só paga os juros referentes ao valor e período que utilizar. O Saque Especial Banespa é uma idéia tão boa que a gente não se conteve e quer que você - nosso cliente preferencial - desfrute dos seus benefícios desde já, antes do lançamento oficial. O crédito já está nas suas mãos, e os nossos gerentes à sua disposição para maiores esclarecimentos."

Logo após o lançamento do Saque Especial, veio o contingenciamento do crédito nas financeiras, em decorrência do que seriam congelados os montantes de crédito então concedidos às pessoas físicas. Com a migração para o banco das operações que, na financeira, eram feitas às pessoas jurídicas em nome de seus sócios, na Carteira do Saque Especial, pudemos continuar atendendo ao mercado de forma crescente, o que nos propiciou a manutenção de bons resultados, não obstante $o$ impacto do Plano Cruzado.

\section{UMA FORMA SIMPLES E} DESCOMPLICADA DO USO DO MARKETING MIX. UMA RECEITA DE SUCESSO

Um bom plano de marketing começa invariavelmente pela definição de um objetivo, seguido da montagem de uma estratégia mercadológica capaz de atingi-lo.

No caso da Financeira Banespa, isso não foi diferente. Senão vejamos:

1. Objetivo: crescimento.

Aumento de seu Market Share, de
Quadro 2

Consumidores

\begin{tabular}{lcc}
\hline & Atuais & Novos \\
\hline Produtos atuais & Penetração do mercado & Desenvolvimento do mercado \\
\hline Produtos novos & Desenvolvimento do mercado & Diversificação \\
\hline
\end{tabular}


tal forma que, deixando a posição pouco significativa que ocupava na classificação, assumisse uma colocação entre as empresas-líderes do setor.

\section{Estratégia básica: a de} penetração de mercado. Segundo o quadro de Igor Ansoff, dentre as várias alternativas estratégicas, a financeira optou por crescer com os produtos atuais, junto aos seus consumidores atuais.

3. De que forças e fraquezas dispunha:

\subsection{Forças}

- imagem institucional;

- excelente cadastro de clientes;

- taxas (peças) competitivas;

- boa rede de distribuição

(agências);

- recursos disponiveis para a comunicação;

- boa agência de propaganda.

\subsection{Fraquezas}

- burocratização excessiva; - forte ação da concorrência, bem posicionada na oferta do produto em questão;

- venda pessoal (direcionamento do trabalho de vendas pelo pessoal de agência e treinamento); - adequação do produto.

Definidos o objetivo principal e a estratégia básica, definidas as forças e fraquezas da empresa, pôde-se então alinhavar adequadamente a sua seqüência de ações mercadológicas, através dos seguintes passos:

\section{Pesquisas}

1.1 De produto: qual o melhor produto para se aplicar a estratégia de penetração, dentre os disponíveis.

1.2 Junto à venda pessoal: levantamento de sua realidade, dos problemas do seu dia-a-dia, a fim de que fosse possível definir um caminho que permitisse maximizar o desempenho da equipe, direcionando-o para $o$ cumprimento dos objetivos do plano.

1.3 Consumidores: pesquisa e análise dos fatores que estimulavam e/ou inibiam o consumidor a tomar um empréstimo. A complexidade (para o consumidor) do preenchimento de documentos, sua dificuldade de decidir sobre prazos, taxas, custo de dinheiro etc. foram fatos aqui pesquisados e analisados.

$\mathrm{O}$ que as pesquisas indicaram? Indicaram que o produto deveria ser o crédito pessual, descomplicado, simples e rápido de ser obtido e vendido. Isto levou a financeira a:

\section{Adequação do produto: cria-} ram-se condições para que ele (crédito pessoal), no seu conceito, na sua essência, fosse visto pelo consumidor como bom, barato e fácil de ser adquirido (quebraram-se as barreiras das dificuldades apresentadas $a$ priori).

\section{Estratégia de comunicação:} contando com um bom cadastro de clientes (aspecto quantitativo) a financeira optou pelo esquema de marketing direto, valendo-se da mala direta como veículo da comunicação. No marketing direto diz-se que (entre outras coisas):

- o melhor cliente é aquele que já é seu cliente, portanto, a lista de clientes é aquela que sempre gera melhores respostas;

- o nome constante do cadastro (da listagem) deve ser "capturado pelo marketing direto num programa organizado de contatos, para que inclusive se tenha a possibilidade de explorá-lo melhor (venda de mais produtos, de maiores volumes ou em número maior de oportunidades).

Provavelmente, após a primeira remessa de mala direta, verificados os índices de respostas, já teria a financeira condições de antever os resultados futuros das novas remessas que seriam enviadas. Um dos fatos mais relevantes e importantes do marketing direto é que ele se presta muito facilmente à realização de testes. Isto, obviamente, leva a uma outra situação característica: mensurabilidade da operação.

Por incrível que pareça, a lista de clientes (a lista doméstica), apesar de ser excelente sob o ponto de vista de nível de resposta, é quase sempre a mais negligenciada pelas empresas em geral. Este erro o Banespa não cometeu. Ao contrário.

A oferta que foi feita via mala direta primava, como sempre deve acontecer, pela simplicidade e objetividade. Era fácil de ser lida e fácil de ser entendida. Os planos de pagamento, explicitados no verso, facilitava ainda mais o entendimento e a decisão do cliente. Como peça promocional, era impecável. Falar pouco foi um dos pontos altos da mesma, com méritos para a sua objetividade.

\section{Estratégia de distribuição e} venda pessoal: a maximização das utilidades de tempo, lugar e posse, que é a função da distribuição, nesse caso não foi difícil de ser obtida, já que os clientes e pontos de venda eram cativos e já interagiam, num nível de contato que, se não era ótimo, era pelo menos razoável.

Restava oferecer ao cliente as facilidades de rapidez na transação, o que foi obtido através do treinamento do vendedor e da redução da sua carga de papéis e assinaturas (contratos e ficha cadastral), para que tivesse o seu diálogo com $o$ cliente facilitado e reduzido, em termos de tempo médio.

5. Estratégia de preços: o preço do dinheiro, neste caso, não foi um problema muito sério, por duas razões básicas: primeiro, porque o Banespa sabidamente opera com taxas de aplicação bastante competitivas. Segundo, porque o consumidor médio raciocina mais com o valor da prestação (muito

bem detalhado, com várias operações neste caso) do que com a taxa de juros.

Resultado da estratégia: a financeira, com esse esquema bastante simples e objetivo (como aliás deveriam ser todos os planos), acabou chegando aonde pretendia.

Mais do que um sucesso,o expediente revela um caminho que ainda pode gerar bons frutos no futuro. 